\title{
A Rare Case of Unicuspid Aortic Valve with Postoperative Heart Block
}

Divya Ravi ${ }^{1}$, Muhammad Siddique Pir ${ }^{1}$, Najam Saqib ${ }^{2}$, Gaurav Patel ${ }^{3}$, Haitham Abughnia ${ }^{4}$

1. Internal Medicine, The Wright Center for Graduate Medical Education, Scranton, USA 2. Internal Medicine, Wright Center for Graduate Medical Education, Scranton, USA 3. Cardiology, The Wright Center for Graduate Medical Education, Scranton, USA 4. Cardiology, The Wright Center for Graduate Medical Education, Clark Summit, USA

Corresponding author: Divya Ravi, drdivravi@gmail.com

\begin{abstract}
Unicuspid aortic valve (UAV) is an extremely rare cause of aortic stenosis, accounting for about $0.02 \%$ of the adult population. We present a rare case of UAV in a young woman who presented with dyspnea on exertion. She underwent extensive work-up, including a transthoracic echocardiogram, which was notable for critical aortic stenosis with significant pulmonary hypertension. A subsequent transesophageal echocardiogram confirmed the severe degree of aortic stenosis and revealed the possibility of a UAV. She was referred to a cardiothoracic surgeon and underwent bioprosthetic aortic valve replacement. Intraoperative evaluation confirmed the rare occurrence of a UAV. Postoperative course was complicated by complete heart block necessitating pacemaker placement.
\end{abstract}

Categories: Cardiac/Thoracic/Vascular Surgery, Cardiology

Keywords: congenital, aortic stenosis, unicuspid aortic valve, pacemaker

\section{Introduction}

Aortic stenosis is the abnormal narrowing of the aortic valve outlet. It is one of the most common valvular lesions, with an estimated prevalence of $2 \%-9 \%$ in the general adult population above the age of 65 years [1]. Unicuspid aortic valve (UAV) is an extremely rare cause of aortic stenosis, accounting for $0.02 \%$ of the adult population [2]. We present a case of UAV in a young woman who eventually underwent successful bioprosthetic aortic valve replacement.

\section{Case Presentation}

We report a case of a 28-year-old woman who presented to the office with complaints of progressive exertional dyspnea of three months duration. Of note, she was diagnosed with congenital aortic valve stenosis at birth and underwent balloon valvuloplasty as a neonate. She was followed by a pediatric cardiologist through her childhood and reported no difficulty with moderate-to-strenuous activity as an adolescent. However, as an adult, she spent several years of her life outside the country and was unable to follow up with a cardiologist during that interim period. On return to the States, she re-established care in light of her ongoing symptoms. She reported severe dyspnea on exertion with occasional lightheadedness

Received 06/02/2019 Review began 07/19/2019 Review ended 07/23/2019 Published 07/31/2019

\section{() Copyright 2019}

Ravi et al. This is an open access article distributed under the terms of the Creative Commons Attribution License CC-BY 3.0., which permits unrestricted use, distribution, and reproduction in any medium, provided the original author and source are credited. and palpitations. A review of systems was negative except the aforementioned symptoms. On exam, she had an ejection systolic murmur with a click, best heard at the apex, and radiating to her neck.

Electrocardiography (Figure 1) was unremarkable while a transthoracic echocardiogram (TTE) (Figures 2 and 3) was notable for critical aortic stenosis (valve area $0.5 \mathrm{~cm}^{2}$, mean gradient $40 \mathrm{~mm}$ of $\mathrm{Hg}$ ) with significant pulmonary hypertension (pulmonary artery pressure $80-84 \mathrm{~mm} \mathrm{Hg}$ systolic). Both ventricles appeared grossly normal with an estimated ejection fraction $55 \%$. We consulted an adult congenital heart disease specialist and performed a transesophageal echocardiogram (TEE). The TEE confirmed the degree of aortic stenosis and indicated the possibility of a UAV.

She was referred to a cardiothoracic surgeon and underwent bioprosthetic aortic valve replacement. The intraoperative evaluation confirmed the rare occurrence of a UAV. However, the postoperative course was complicated by complete heart block with pacemaker placement. 


\section{Cureus}

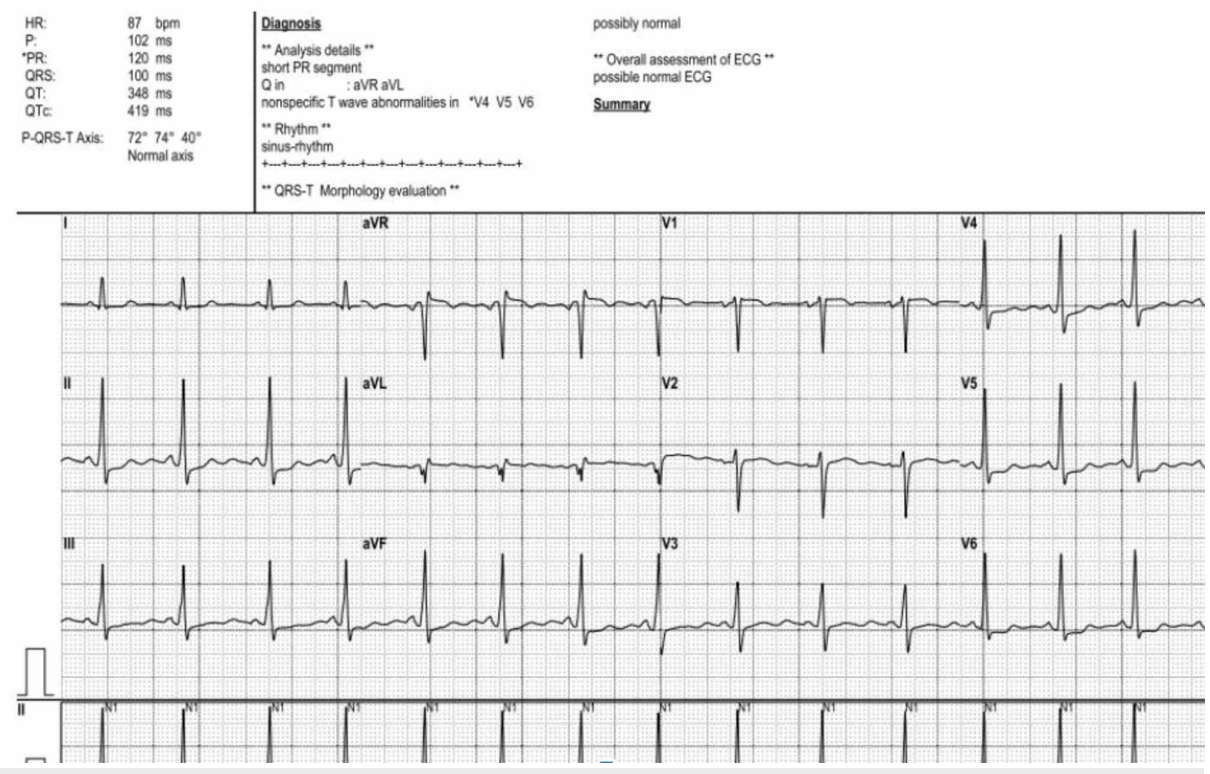

FIGURE 1: Grossly Unremarkable Electrocardiogram of the Patient

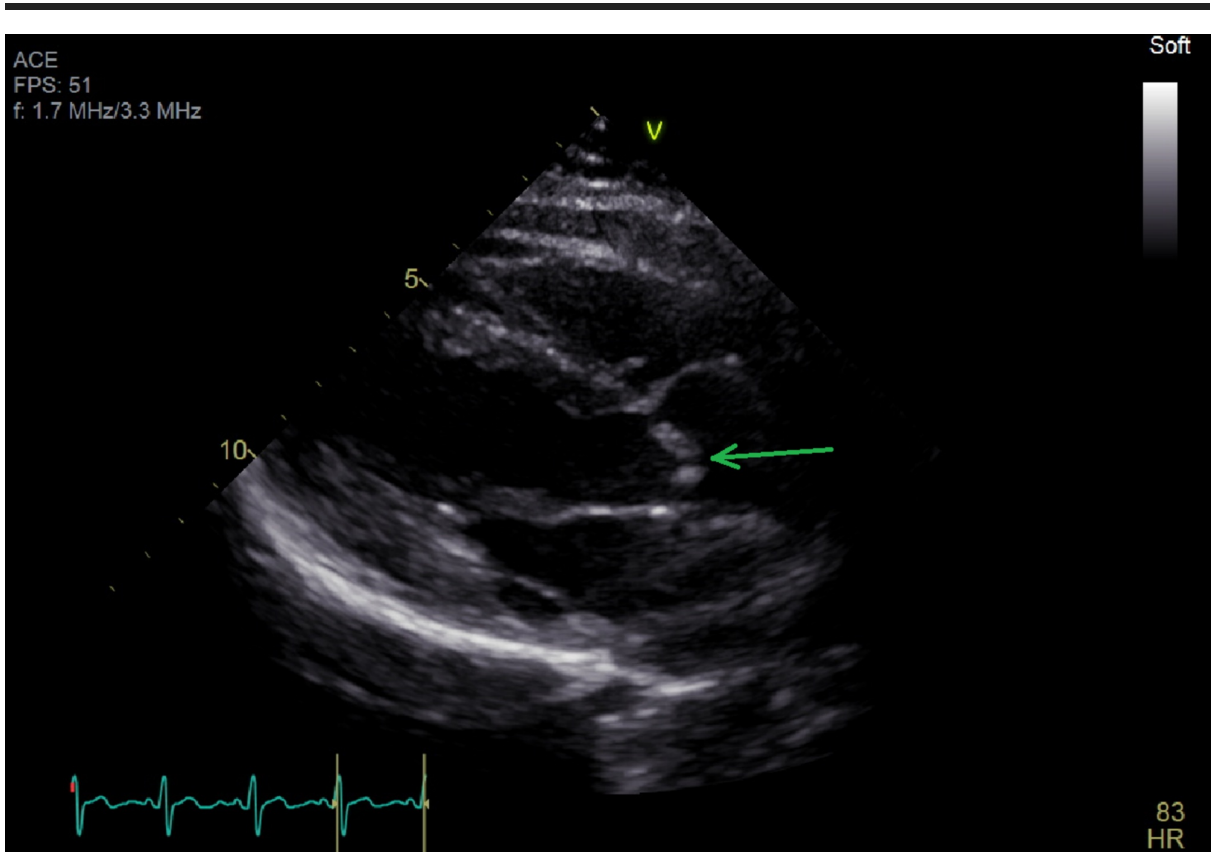

FIGURE 2: Parasternal Long Axis View Showing Eccentric Closure of Aortic Valve (arrow) 


\section{Cureus}

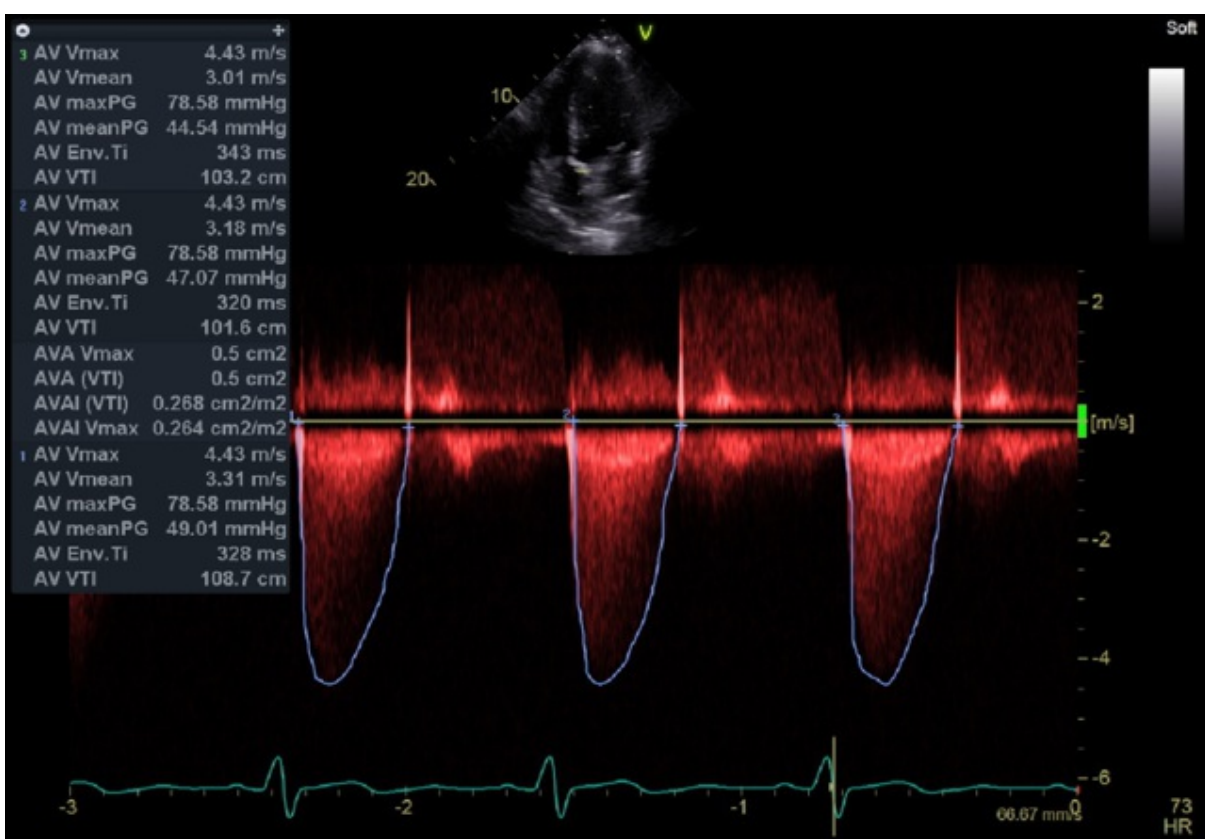

FIGURE 3: Transthoracic Echocardiogram showing Aortic Valve Area, Peak Velocity and Mean Gradient Consistent with Severe Aortic Stenosis

\section{Discussion}

This case report was notable for not only the rare presentation of UAV in a young female patient but also the postoperative complication of complete heart block warranting a pacemaker.

The unicuspid aortic valve is a rare congenital anomaly with an annual incidence of less than $0.02 \%$ in the general adult population with four times higher prevalence among males [2]. Patients with UAV may present with dyspnea and a systolic murmur from underlying heart failure and aortic stenosis, respectively; this combination, especially in a young patient, must raise suspicion of a UAV. A review by Mookadam et al reported that nearly $41 \%$ of the cases manifested with isolated aortic stenosis and $28 \%$ had aortic stenosis with or without regurgitation [3].

While a majority of UAV cases are diagnosed on autopsy or pathological examination of the excised valve, the diagnostic modality best suited to clinically diagnose UAV is a three-dimensional TEE [4]. A TTE is unlikely to show enough detail to differentiate a unicuspid from a bicuspid aortic valve. Rarely, the diagnosis is made on intraoperative visualization of the valve $[2,4]$. As seen in our case, a TTE was only able to identify the presence of aortic stenosis, a follow-up TEE raised suspicion of UAV which was subsequently confirmed during the open surgical procedure.

Another distinguishing feature of this case is the postoperative development of heart block. The mechanism is related to the close anatomical proximity between the aortic valve and conduction system that predisposes to perioperative conduction abnormalities with aortic valve surgeries. While the development of conduction abnormality among patients undergoing isolated aortic valve replacement is relatively significant (up to 1 in 12, in a study by Dawkins et al) [5], we could only identify two other case reports of UAV in the literature that described postoperative complete heart block requiring pacemaker placement [6-7].

\section{Conclusions}

This report describes a rare presentation of aortic stenosis in a young female adult in the setting of a known history of congenital heart disease. Our case adds to the body of literature by highlighting key diagnostic modalities such as transesophageal echocardiogram and intraoperative visualization that can aid in the diagnosis of this rare anomaly. Additionally, this case outlines the possibility of perioperative conduction abnormalities associated with aortic valve surgeries.

\section{Additional Information}

\section{Disclosures}


Human subjects: Consent was obtained by all participants in this study. The Wright Center for Graduate Medical Education Institutional Review Board (WCGME-IRB) issued approval n/a. DATE: May 30, 2019 TO: Divya Ravi, MD MPH FROM: The Wright Center for Graduate Medical Education Institutional Review Board (WCGME-IRB) PROJECT TITLE: [1442756-1] A Rare Case of Unicuspid Aortic Valve SUBMISSION TYPE: New Project ACTION: DETERMINATION OF EXEMPT STATUS DECISION DATE: May 30, 2019 REVIEW CATEGORY: Exemption category \# 4 Thank you for your submission of New Project materials for this project. The Wright Center for Graduate Medical Education Institutional Review Board (WCGME-IRB) has determined this project is EXEMPT FROM IRB REVIEW according to federal regulations. We will retain a copy of this correspondence within our records. If you have any questions, please contact Kathleen Uhranowsky at 570-591-5197 or uhranowskyk@thewrightcenter.org. Please include your project title and reference number in all correspondence with this committee. Conflicts of interest: In compliance with the ICMJE uniform disclosure form, all authors declare the following: Payment/services info: All authors have declared that no financial support was received from any organization for the submitted work. Financial relationships: All authors have declared that they have no financial relationships at present or within the previous three years with any organizations that might have an interest in the submitted work. Other relationships: All authors have declared that there are no other relationships or activities that could appear to have influenced the submitted work.

\section{References}

1. Subramanian R, Olson LJ, Edwards WD: Surgical pathology of combined aortic stenosis and insufficiency: a study of 213 cases. Mayo Clin Proc. 1985, 60:247-254. 10.1016/s0025-6196(12)60317-6

2. Novaro GM, Mishra M, Griffin BP: Incidence and echocardiographic features of congenital unicuspid aortic valve in an adult population. J Heart Valve Dis. 2003, 12:674-678.

3. Mookadam F, Thota VR, Garcia-Lopez AM, Emani UR, Alharthi MS, Zamorano J, Khandheria BK: Unicuspid aortic valve in adults: a systematic review. J Heart Valve Dis. 2010, 19:79-85.

4. Chang HH, Cheng CL, Wang WC, Huang PJ, Lin SY: Assessment of unicuspid aortic valve stenosis using multimodality imaging, X-ray radiography and Raman analysis. Int Heart J. 2019, 60:482-488. 10.1536/ihj.18-338

5. Dawkins S, Hobson AR, Kalra PR: Permanent pacemaker implantation after isolated aortic valve replacement: incidence, indications, and predictors. Ann Thorac Surg. 2008, 85:108-112. 10.1016/j.athoracsur.2007.08.024

6. Armstrong J, Crawford J, Arnautovic J: Unicuspid aortic valve replacement with development of complete heart block: a case report. Eur Heart J Case Rep. 2019, 3:026. 10.1093/ehjcr/ytz026

7. Singh S, Ghayal P, Mathur A, et al.: Unicuspid unicommissural aortic valve: an extremely rare congenital anomaly. Tex Heart Inst J. 2015, 42:273-276. 10.14503/THIJ-13-3634 